\title{
O ATIVISMO DE BERTHA LUTZ PARA PRESERVAÇÃO DA NATUREZA: SOBRE OS PARQUES NACIONAIS, FISCALIZAÇÃO E PARECERES EM FAVOR DA CONSERVAÇÃO INTEGRAL NO ESTADO DO RIO DE JANEIRO - BRASIL (1950-1954)
}

\section{BERTHA LUTZ'S ACTIVISM FOR THE PRESERVATION OF NATURE"ON NATIONAL PARKS, SUPERVISION AND REPORTS IN FAVOR OF INTEGRAL CONSERVATION IN THE STATE OF RIO DE JANEIRO (1950-1954)}

\author{
Ana Beatriz de MENEZES RIBEIRO ${ }^{1,2}$; Luci de SENNA-VALLE ${ }^{1,2}$; Maria Franco Trindade MEDEIROS ${ }^{1,2}$
}

${ }^{1}$ Programa de Pós-graduação em Ciências Biológicas (Botânica), Museu Nacional/Universidade Federal do Rio de Janeiro ${ }^{2}$ Laboratório Interativo em Etnobotânica, Departamento de Botânica, Museu Nacional/UFRJ, Quinta da Boa Vista, São Cristóvão, 20940040, Rio de Janeiro, RJ, Brasil.

*anabeamenezes@gmail.com

Submitted: 07/08/2020; Accepted: 10/12/2021; Published: 26/02/2021

\section{RESUMO}

Este texto apresenta um painel da atuação de Bertha Lutz, cientista brasileira e naturalista, descrita por si mesma. Trata-se da apresentação de uma documentação dos arquivos da Seção de Memória e Arquivo (SEMEAR) do Museu Nacional, que foi extinto pelo incêndio do dia 02 de setembro de 2018. Os originais datilografados de Bertha Lutz demostram sua visão da situação ambiental por diversas localidades fluminenses, particularmente sobre a flora de Mata Atlântica, no entorno dos parques nacionais até as fronteiras do estado do Rio de Janeiro com São Paulo e Minas Gerais. O Relatório de 1954 foi enviado ao Ministério da Agricultura, após uma expedição científica de monitoramento e de fiscalização, por Bertha Lutz pessoalmente, entre os anos de 1953 e 1954. Acompanhada de um técnico do Museu Nacional, Sr. Venâncio Fernandes, contou com o apoio do pessoal das localidades e funcionários dos parques. As localidades foram escolhidas a partir de antigos caminhos de naturalistas e áreas conhecidas de interesse científico para coleta de batráquios, como o Itatiaia e a Serra dos Órgãos. Bertha Lutz trouxe um alerta e a recomendação ao Ministério da Agricultura: aumentar os territórios protegidos e a conservação integral das florestas nativas ainda existentes fora das unidades, ampliando a criação de parques nacionais no Brasil, especialmente nos estados do Rio de Janeiro, São Paulo e Minas Gerais.

PALAVRAS-CHAVE: Conservação, Ecobiologia, Mata Atlântica do estado do Rio de Janeiro, Museu Nacional, Parque Nacional da Serra dos Órgãos.

\begin{abstract}
Brazilian scientist, naturalist Bertha Maria Julia Lutz, thus described by herself. The typed original works of Bertha Lutz was at the Memory Archive Section (SEMEAR) of the National Museum from Rio de Janeiro, which was extinguished by the fire on September 2, 2018. This Bertha Lutz's deed demonstrates her in-field vision of the environmental situation of many Rio de Janeiro State localities, especially the situation of the flora surrounding national parks up to the borders of São Paulo and Minas Gerais states. The relatory of 1954 was sent to the Agriculture Ministry after a scientific expedition of monitoring and inspection led personally by Bertha Lutz between 1953 and
\end{abstract}


1954. Followed in the expedition by a technician of the National Museum, Mr Venâncio Fernandes, they had the support of the local inhabitants. The locations were chosen among ways previously used by other naturalists and known places for the collection of batrachian species, as Itatiaia and Serra dos Órgãos mountains. Bertha Lutz recommended to the Ministry of Agriculture the expansion of the protected territories and the integral conservation of the native original forests, still remaining outside the conservation units expanding the creation of national parks in Brazil, especially in the states of Rio de Janeiro, São Paulo and Minas Gerais.

KEYWORDS: Conservation, Ecobiology, National Museum, Rio de Janeiro state Atlantic Rain Forest, Serra dos Órgãos National Park.

\section{INTRODUÇÃO}

Ao longo dos séculos, registros sobre as observações de naturalistas foram produzidos em palavras e imagens. Esses documentos criados no passado podem hoje em dia ser acessados, sistematizados e ganhar um novo significado para a humanidade quando por exemplo, tais registros científicos produzidos em outros momentos históricos evocam uma discussão atual acerca da conservação da natureza que abarque ambos os sistemas socioecológicos e a sociobiodiversidade. Relatos de viajantes que percorreram o território brasileiro entre os séculos XVI e XX nos apresentam as impressões de mulheres e homens da ciência, frequentemente vindos de países longínquos, prestando serviços às instituições de pesquisa ou sociedades científicas, ou ainda, aos Estados.

Os esforços científicos visavam à produção de uma história natural das colônias e, mais adiante na história, dos países independentes. Estas ações apoiavam-se num amplo levantamento das produções acerca dos reinos vegetal, animal e mineral, visando à descoberta de novas espécies e à busca por riquezas e recursos naturais, que servissem de matéria-prima ao desenvolvimento científico e econômico do Império e, depois, do próprio país (PATACA e PINHEIRO, 2005; PATACA, 2011). Nestes relatos de viajantes, comumente encontramos estudos sobre o continente, o interior, limites de fronteira, processos de contato e aproximação com realidades distintas às realidades de origem dos naturalistas. Além disto, vemos observações em formas gráficas diversas, sobre mulheres e homens presentes nos territórios percorridos.

Dentro dessas missões científicas, encontramos um conjunto de naturalistas que se empenharam em exercer a ciência e, assim, vivenciaram experiências diversas pelo território brasileiro. Produziram estudos, relatos, cadernos de viagens e uma documentação administrativa que nos informa sobre um levantamento dos recursos naturais das regiões 
MENEZES RIBEIRO, A. B; SENNA-VALE, L; MEDEIROS, M.F.T. O ativismo de Bertha Lutz para preservação da natureza: sobre os parques nacionais, fiscalização e pareceres em favor da conservação integral no estado do Rio de Janeiro Brasil (1950-1954). Ethnoscientia v.6 n. 2, especial, 2021. DOI: 10.22276/ethnoscientia.v6i2.331

visitadas. Especialmente nos séculos XVIII e XIX, esses movimentos científicos empreendidos pelos naturalistas viajantes (LEITE, 1995) caracterizam-se como esforços para obter o conhecimento da natureza por meio dessas viagens científicas, no intento de favorecer o ser humano quanto ao uso desses recursos naturais em suas mais diferentes necessidades diárias, como na alimentação e na saúde (KURY, 2001a, b). Neste contexto, naturalistas brasileiros e estrangeiros, tais como Alexandre Rodrigues Ferreira (1756-1815), Manuel Galvão da Silva (Século XVIII) e Carl Friedrick Philipp von Martius (1794-1868), desenvolveram seus estudos em território brasileiro.

Já no século XX, os empenhos científicos em torno da construção de identidades, territorialidade e natureza continuaram, mas certamente outras questões foram sendo incorporadas aos interesses investigativos dos naturalistas. Uma delas está relacionada ao processo dinâmico de construção de identidade científica e política brasileira, voltada à conservação da natureza. Neste âmbito, naturalistas como Bertha Maria Júlia Lutz (18941976), junto a Alberto José de Sampaio (1881-1946) e Edgard Roquette-Pinto (1884-1954), entre outros não menos importantes, defenderam com sucesso a preservação da natureza e políticas de conservação sob a forma de parques nacionais Brasil, especialmente na conjuntura política e científica da Era Vargas, nas décadas de 1930-1940 (DRUMMOND e FRANCO, 2005; DRUMMOND, 2009; MENEZES-RIBEIRO, 2019).

Sobre a contribuição feminina para a ciência brasileira, selecionamos uma questão original de atuação da cientista Bertha Lutz, que esteve em toda sua vida profissional ligada ao Museu Nacional, instituição de pesquisa e seção do outrora Ministério da Agricultura Indústria e Comércio - o MAIC, depois rebatizado de Ministério da Agricultura - MA. Bertha Lutz foi aprovada em concurso e iniciou seus trabalhos no Museu Nacional do Rio de Janeiro em 1919, tornando-se, naquele momento, a segunda mulher servidora pública do Brasil. Naturalista, especializada em anfíbios, foi professora por mais de 40 anos na referida instituição de pesquisa. Em princípios do século XX, atuou como líder na campanha pelo voto das mulheres no Brasil, direito conquistado em 1932. Após quatro anos, ingressou no cenário da política federal, quando desempenhou o cargo de Deputada Federal (SÁ, 2018).

Bertha Lutz e a sua interação com o grupo de pessoas relacionadas às causas da preservação da natureza na década de 1930, mais especificamente aos parques nacionais brasileiros, foi um motivo de importantes questionamentos da pesquisa de Menezes-Ribeiro (2019) sobre a criação do Parque Nacional da Serra dos Órgãos - o PARNASO -, em 1939. Antes das documentações de Bertha Lutz que aqui apresentamos, não havíamos identificado ainda uma documentação primária que confirmasse a atuação direta dessa 
cientista em relação ao PARNASO ou aos projetos de criação dos primeiros parques nacionais brasileiros.

Considerando tal ineditismo documental e a atuação feminina na ciência brasileira em prol da conservação da natureza, este trabalho tem como objetivo fazer a apresentação de uma documentação depositada no Arquivo Histórico do Museu Nacional/UFRJ e no Arquivo Nacional-AN, que demonstrou o ativismo científico pela conservação da Mata Atlântica, da cientista brasileira, naturalista, botânica e zoóloga Bertha Lutz, descrita por si mesma.

\section{MATERIAL E MÉTODO}

\subsection{Procedimentos para a análise documental}

A pesquisa desenvolvida foi de caráter histórico, aplicada para a construção da história ambiental e institucional de uma Unidade de Conservação-UC, no caso, o Parque Nacional da Serra dos Órgãos.

A escolha da documentação aqui analisada fez parte de uma pesquisa maior sobre a política de proteção à natureza no Brasil, relacionando os envolvidos com a criação dos parques nacionais brasileiros, especificamente a criação do Parque Nacional da Serra dos Órgãos (PARNASO) em 1939 (ver dissertação de mestrado de MENEZES-RIBEIRO, 2019).

Iniciamos a busca bibliográfica entre os anos 2017-2018, com foco em documentações primárias (originais) e secundárias (produzidas por terceiros) nas cidades do Rio de Janeiro, Teresópolis e no Museu Imperial de Petrópolis, cidades limítrofes ao território do parque, onde os fatos históricos da criação deste terceiro parque nacional brasileiro pudessem estar depositados. A busca foi feita através da comunicação on-line com arquivistas e bibliotecárias e em bases de dados on-line e físicas, bem como em arquivos e bibliotecas nacionais e estrangeiras, de interesse histórico, realizadas nos seguintes locais: Jardim Botânico do Rio de Janeiro - Biblioteca Barbosa Rodrigues, Arquivo Nacional, Centro de Pesquisa e Documentação da Fundação Getúlio Vargas, Biblioteca Nacional, Biblioteca e Arquivo Histórico do Museu Nacional, Biblioteca do Instituto de Filosofia e Ciências Sociais da Universidade Federal do Rio de Janeiro, Biblioteca de Chicago on-line, Bibliothèque Nationale de France - François Mitterrand, Bibliothèque Centrale du Muséum National d'Histoire Naturelle, Biblioteca do Museu 
MENEZES RIBEIRO, A. B; SENNA-VALE, L; MEDEIROS, M.F.T. O ativismo de Bertha Lutz para preservação da natureza: sobre os parques nacionais, fiscalização e pareceres em favor da conservação integral no estado do Rio de Janeiro Brasil (1950-1954). Ethnoscientia v.6 n. 2, especial, 2021. DOI: 10.22276/ethnoscientia.v6i2.331

Imperial de Petrópolis on-line, Biblioteca Nacional (obras raras e hemeroteca) e Biblioteca do Clube de Engenharia do Rio de Janeiro.

A busca bibliográfica foi alternada com quatro visitas de campo à sede administrativa principal do PARNASO em Teresópolis para consulta à biblioteca, documentação institucional e conversas com os mais velhos e todo o pessoal interno, cientistas, estagiários e pessoal administrativo do Parque Nacional da Serra dos Órgãos para que nos apontassem a existência e a localização de outras fontes de pesquisa na cidade de Teresópolis. Essas indicações sobre a temática resultaram no acesso ao acervo particular e a arquivos de Wanderley Peres do Jornal $O$ Diário e também ao material documental depositado na Casa da Memória de Teresópolis - Artur Dalmasso.

As buscas foram centradas na década de 1930-1940. Especificamente buscávamos relações com a criação do Parque Nacional da Serra dos Órgãos em 1939, sua origem e desdobramentos. As documentações selecionadas e revisadas, na categoria escrita, foram: obras literárias, jornalísticas e documentos institucionais; e na categoria imagemiconografia: pinturas, desenhos e fotografias de época, juntamente com uma palestra em áudio da década de 1950.

Todas as documentações sobre a criação do PARNASO, incluindo as fontes de Bertha Lutz aqui analisadas, foram copiadas por scanner ou fotografias digitais por dispositivo móvel (celular).

O conjunto total de documentos selecionados para a pesquisa foi batizado e intitulado "Safra do PARNASO" pelo antropólogo Arno Vogel. O conceito de uma safra sugere assim, o resultado de um ano e uma colheita variada nos arquivos e fundos de memória institucionais do Rio de Janeiro e de Teresópolis: Atos Legais, artigos, notícias sobre o Ministério da Agricultura, sobre os clubes de serviço, os centros de excursionismo e montanhismo, artigos de jornais, revistas, livros raros, imagens etc. A Safra do PARNASO está depositada nas instituições Escola Nacional de Botânica Tropical, Instituto de Pesquisas Jardim Botânico do Rio de Janeiro (EBNT-JBRJ), no Rio de Janeiro, e no setor científico de monitoramento da biodiversidade, Biblioteca do PARNASO-ICMBIO em Teresópolis-RJ (MENEZES-RIBEIRO, 2019). 
MENEZES RIBEIRO, A. B; SENNA-VALE, L; MEDEIROS, M.F.T. O ativismo de Bertha Lutz para preservação da natureza: sobre os parques nacionais, fiscalização e pareceres em favor da conservação integral no estado do Rio de Janeiro Brasil (1950-1954). Ethnoscientia v.6 n. 2, especial, 2021. DOI: 10.22276/ethnoscientia.v6i2.331

\subsubsection{Fontes documentais relacionadas à concepção de parques nacionais}

Uma primeira etapa de desenvolvimento da pesquisa foi a busca e organização das origens do conceito de parques nacionais e da ideia de se criar esse tipo de unidade de conservação, pela primeira vez nos Estados Unidos e, mais de sessenta anos depois, no Brasil. Desde meados do século XIX, com a chamada melhor ideia americana ou the America idea, temos a fundação do primeiro modelo de parque nacional, Yellowstone National Park, nos Estados Unidos em 1872 (HEACOX, 2004). Mais de sessenta anos depois, a belíssima descrição de André Pinto Rebouças (1838-1898) - engenheiro e botânico no II Império, que esteve na região da Serra dos Órgãos quando jovem militar unindo a ideia norte-americana de um national park ao turismo de elite, empreendimento muito rentável que presenciou e frequentou nos Estados Unidos e na Europa. Assim, Rebouças propôs a criação de parques regionais no Brasil, com modernas estruturas de engenharia, para a conservação e 'comoditização' da natureza, inaugurando entre nós o turismo de base ecológica visando à preservação de vastas regiões do Brasil (REBOUÇAS 1876, 1938; MENEZES-RIBEIRO, 2019).

Uma segunda etapa da busca documental foi pesquisarmos, a partir dos anos 19301940, na era da criação dos três parques nacionais brasileiros pelo presidente Getúlio Vargas, especificamente sobre a história da criação do Parque Nacional da Serra dos Órgãos em 1939. Buscamos a participação de personagens políticos, escritores, jornalistas e funcionários do Ministério da Agricultura, Indústria e Comércio-MAIC, que incluía diversas instituições, tais como o Jardim Botânico do Rio de Janeiro e o Museu Nacional.

O Arquivo Nacional nos forneceu também uma lista, que havia sido elaborada em cooperação com o arquivo histórico do Museu Nacional - SEMEAR. Ali obtivemos detalhes biográficos e quantidade de arquivos de todos os cientistas do Museu Nacional entre 1920-1970. Esta lista interna denominada Folder de 2009, feita sob a orientação técnica da arquivista Sílvia Nirita de Moura Estevão, indicou-nos o nome de vários cientistas, dentre os quais Alberto José de Sampaio, Bertha Lutz e Edgard Roquette-Pinto, que certamente estiveram envolvidos em questões da preservação da natureza e na criação dos parques nacionais brasileiros.

Os documentos relacionados à década de 1930-1950 guardam estreita relação com o Museu Nacional e seus cientistas, como Alberto José de Sampaio, Edgard Roquette-Pinto em parceria com Laurence Vail Coleman, da American Association of Museums. Surpreendeu-nos o pioneirismo do Museu Nacional em 1933, no projeto de Roquette-Pinto 
e Vail Coleman, para um primeiro parque nacional em territórios do atual PARNASO. O Parque Guanabara-Serra dos Orgãos, que existiu apenas como um projeto do Museu Nacional, incluiu uma organização detalhada para um parque científico, primeiro exercício para a práxis da nova ciência da conservação que nascia no Brasil e no mundo. Os ecossistemas em conectividade e cooperação científica abririam o novo parque nacional a todos os países e cientistas visitantes, uma proposta que protegeria integralmente a natureza, desde os fundos da Baía de Guanabara até os alto-montanos da Serra dos Órgãos (ROQUETTE-PINTO,1933; CASAZZA, MENEZES-RIBEIRO, 2019).

\subsubsection{Fontes documentais acerca da atuação de Bertha Lutz}

As documentações primárias ou originais sobre o envolvimento de nossa homenageada nas causas da preservação da natureza e parques nacionais foram: o relatório de Bertha Lutz (1954) e uma gravação de palestra em áudio sobre reservas e parques do mundo todo na voz da própria Bertha Lutz, que consta sem datação. Considerando a década de sua atuação voltada à temática, foi possível a aproximação desta fonte em áudio para a década de 1950. A sua nomeação ao longo do texto seguiu o indicativo da década de 1950 , sem a precisão do ano, segundo o modelo de citação (195_).

O áudio de Bertha Lutz (1950) está localizado no fundo de Bertha Lutz, no próprio Arquivo Nacional do Rio de Janeiro. Já o Relatório de fiscalização de Bertha Lutz (1954), que pertencia ao SEMEAR do Museu Nacional, está atualmente na Safra do PARNASO e disponível com a primeira autora, através de solicitação por e-mail. Desde os dias seguintes ao incêndio do Museu Nacional, este relatório consta numa lista de dados sobre pesquisadores que obtiveram documentos do Museu para disponibilizá-los no formato digital, assim que solicitados.

Como o registro do Relatório de fiscalização de Bertha Lutz (1954) foi destruído pelo referido incêndio e as documentações da atuação de Bertha Lutz na criação de parques nacionais e na preservação da natureza são muito raras, trouxemos uma análise do seu áudio e apresentamos pela primeira vez o Relatório da excursão de fiscalização de 1954.

A gravação dos trechos do áudio de Bertha Lutz (195_), que transcrevemos para análises, se referiu a uma viagem que a cientista fez para estudar a situação internacional da preservação da natureza, quando retornou para o Brasil trazendo notícias do mundo todo, sobre diversos modelos de parques, reservas e santuários. 


\section{RESULTADOS E DISCUSSÃO}

\subsection{O ativismo científico e político de Bertha Lutz}

Bertha Maria Júlia Lutz nasceu em São Paulo em 1894, filha de Adolpho Lutz (1855-1940), pioneiro da medicina tropical, e Amy Fowler (1869-?), enfermeira de origem inglesa. Bertha Lutz, juntamente com seu pai, conviveu com as florestas serranas em Teresópolis e a Mata Atlântica fluminense, desde a juventude. Depois de formada em Ciências na Sorbonne em 1918, fez concurso para o Museu Nacional em 1919. A partir de então, a Serra dos Órgãos se tornaria seu lar e o Bioma Mata Atlântica fluminense, um campo importante de pesquisas, como observamos na documentação do Relatório de 1954 e no áudio da década de 1950. Bertha Lutz escolheu uma casa retirada em meio à natureza e foi moradora de Teresópolis, até doar sua casa serrana, no fim de sua vida, para que da casa e do sítio se fizesse a sede de um herbário, o Bradeanum (HB) (LUTZ 1950a, 1954b; SÁ, 2018; MENEZES-RIBEIRO, 2019), hoje indexado e com sede na Universidade Estadual do Rio de Janeiro (UERJ), no Rio de Janeiro.

O alcance da personalidade científica, social e política, nas diversas nuances da história de vida de Bertha Lutz, foi um tema analisado por Maria Margareth Lopes (2008). Podemos dizer que a militância feminista, suas ações como cientista ou seu envolvimento no campo político, as inúmeras atividades às quais a cientista brasileira se dedicou foram parte de sua atuação no mundo, e ela o fez de forma indissociável. Assim, Bertha Lutz foi cientista, feminista e política, naturalista e zoóloga, museóloga (LUTZ, 1954; LOPES, 2008) e, como afirmaremos, ambientalista e ativista das causas da conservação da Mata Atlântica e dos parques nacionais brasileiros.

O posicionamento político da cientista brasileira na revisão da constituinte (entre os anos de 1933-1934) e como Deputada Federal (entre 1935-1936) havia sido abertamente em favor dos parques e reservas brasileiros (LOPES, SOUZA e SOMBRIO, 2004; LOPES, 2008). Durante o levantamento de dados, investigando sobre a história da criação do PARNASO em 1939, buscávamos encontrar, entre os personagens envolvidos, um elo entre Bertha Lutz e os parques nacionais.

$\mathrm{Na}$ caixa $\mathrm{n}^{\circ}$ 07, uma surpresa: em meio a alguns poucos documentos sobre os Conselhos de Caça, Pesca e do Conselho das Expedições Científicas e Artísticas, entre os papeis pessoais de Bertha Lutz, encontramos a história perdida da apreensão de material biológico e artefatos indígenas da Amazônia, sem licenciamento, e o encaminhamento da 
MENEZES RIBEIRO, A. B; SENNA-VALE, L; MEDEIROS, M.F.T. O ativismo de Bertha Lutz para preservação da natureza: sobre os parques nacionais, fiscalização e pareceres em favor da conservação integral no estado do Rio de Janeiro Brasil (1950-1954). Ethnoscientia v.6 n. 2, especial, 2021. DOI: 10.22276/ethnoscientia.v6i2.331

coleção para o Museu Nacional. Um visitante alemão que não havia declarado nada ao governo brasileiro fora pego ao embarcar em um navio e seus objetos (nossos) e diário, confiscados. Finalmente, um outro documento, que era exatamente o elo perdido que esperávamos: quatro páginas sobre os parques nacionais no estado do Rio de Janeiro. Bertha Luz havia feito uma excursão científica em várias cidades fluminenses e nos entornos dos parques nacionais do Itatiaia e da Serra dos Órgãos! A cientista havia se envolvido e visitado regiões relevantes para conservação do bioma sudeste de Mata Atlântica. Tínhamos em mãos algo muito especial, um registro de viagem, saídas de campo, uma metodologia, um roteiro, resultados e uma prestação de contas, um relatório datilografado por Bertha Lutz pessoalmente e dirigido ao próprio Ministro da Agricultura.

Eis Bertha Lutz ativamente envolvida na fiscalização e monitoramento das áreas dos parques nacionais, revisitando locais outrora vistos por naturalistas, os parques e as regiões de entorno, hoje conhecidas como "zonas de amortecimento" das unidades de conservação.

A situação dos remanescentes florestais, os costumes agressivos de uso da vegetação, desde a colonização, bem como a história das derrubadas de florestas, ainda se repetiam. O tipo de ocupação agrícola e manejo, a questão da venda de lotes com matas exuberantes, naquele momento da década de 1950, foram anotados pela cientista. Seguiam derrubando e utilizando grandes porções da floresta de Mata Atlântica, fosse nas vilas ou cidades, no entorno das unidades federais, dos parques nacionais do Itatiaia e da Serra dos Órgãos. Remanescentes de ecossistemas de Mata Atlântica da região Sudeste, ainda fora da proteção da União, foram apontados como raros ou insulares em terras fluminenses, em sério risco, se não fossem protegidos (LUTZ, 1954; DEAN,1997).

A expedição de 1953 e a respectiva prestação de contas do Relatório de 1954, como conselheira do Ministério da Agricultura e das Expedições Científicas e Artísticas no Brasil, é a prova física do olhar de Bertha Lutz para a situação das florestas, entre outros ecossistemas e dos parques nacionais no estado do Rio de Janeiro até fronteiras com São Paulo e Minas Gerais ${ }^{1}$.

Funcionários do arquivo do Museu Nacional, diante das perguntas sobre mais um assunto com que Bertha Lutz poderia estar relacionada, durante nossa pesquisa sobre a criação do PARNASO em 1939, se entreolharam de forma brejeira. Ao apresentarem as caixas pessoais de Bertha Lutz para consulta, um curioso assunto foi surgindo, de que todos 
MENEZES RIBEIRO, A. B; SENNA-VALE, L; MEDEIROS, M.F.T. O ativismo de Bertha Lutz para preservação da natureza: sobre os parques nacionais, fiscalização e pareceres em favor da conservação integral no estado do Rio de Janeiro Brasil (1950-1954). Ethnoscientia v.6 n. 2, especial, 2021. DOI: 10.22276/ethnoscientia.v6i2.331

ali também se perguntavam, muitas vezes, diante da imensidão de atividades relacionadas à cientista: "será que a Bertha Lutz dormia?"

\subsection{Relatório de Fiscalização, o campo de Bertha Lutz em 1954 e a palestra em áudio sobre os parques e reservas no mundo todo (195)}

A passagem histórica de Bertha Lutz aqui percorrida compreendeu duas décadas, entre o ingresso no Museu Nacional em 1919, passando por sua trajetória política, feminista e de produção científica, até chegarmos às documentações apresentadas na década de 1950 . O fato é que Bertha Lutz entrou no Museu Nacional como jovem cientista e se constituiu, ao longo dos anos de vida na política e na ciência, como ativista para diversas causas sociais, feministas e como cientista atuante nas críticas à devastação da Mata Atlântica, especialmente na porção sudeste do Brasil. Nesse sentido, Bertha Lutz construiu, em 1954, após uma série de saídas de verificação em campo, propostas ambientalistas para conservação.

Um ano depois da excursão do Museu Nacional de Bertha Lutz e Sr. Venâncio Fernandes, o jornalista Armando Vieira (1955), um dos importantes autores e idealizadores do projeto do parque nacional sediado em Teresópolis - RJ, também nos alertaria sobre os desmatamentos nas fronteiras com o PARNASO, por ocasião das obras da estrada direta Rio-Teresópolis.

As excursões da cientista que incluíram o próprio PARNASO, entre várias outras localidades, trazem o testemunho de Bertha Lutz de visu nas áreas ainda preservadas, como a Bocaina, no Bioma Mata Atlântica, sudeste brasileiro. Nada passou despercebido à cientista, desde a importância da gestão dos administradores das unidades, a ação de moradores, loteadores e, também, como se dizia na época, dos colonos agricultores, em relação ao manejo e trato com a mata nativa. E veio a confirmação: a devastação ${ }^{2}$ continuava sendo a regra, fora das Unidades de Conservação, em diversas localidades fluminenses (LUTZ, 195 ; 1954).

\footnotetext{
2 Sobre a história do uso e a devastação da Mata Atlântica brasileira, consultar Warren Dean (2004). Sobre a terra torturada por três séculos de colonização e agricultura intensiva nas baixadas fluminense e campista, ver Alberto Ribeiro Lamego (1996) em A planície do Solar e da Senzala; primeira edição em 1934.
} 
MENEZES RIBEIRO, A. B; SENNA-VALE, L; MEDEIROS, M.F.T. O ativismo de Bertha Lutz para preservação da natureza: sobre os parques nacionais, fiscalização e pareceres em favor da conservação integral no estado do Rio de Janeiro Brasil (1950-1954). Ethnoscientia v.6 n. 2, especial, 2021. DOI: 10.22276/ethnoscientia.v6i2.331

Bertha fez a análise da situação ambiental, de Mata Atlântica brasileira sudeste, e um apelo à preservação: "fora das fronteiras dos parques nacionais", ainda sob o Governo Vargas. Em uma rara fotografia de época vemos Bertha Lutz e Getúlio Vargas (Figura1).

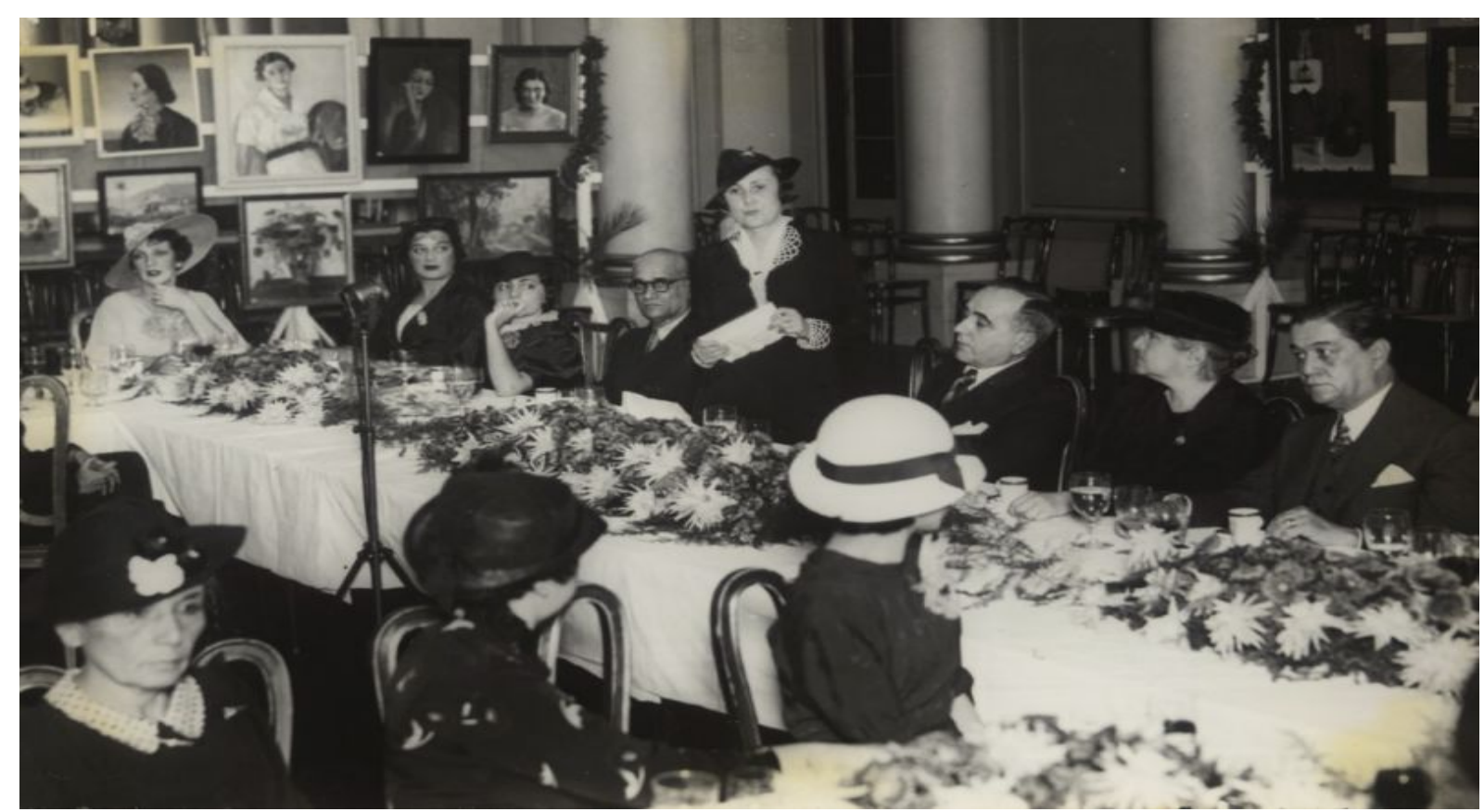

Figura 1: A cientista Bertha Lutz e feministas em solenidade: almoço oferecido a Getúlio Vargas por ocasião do III Congresso Nacional Feminista. Salões do Automóvel Clube do Brasil, ao lado do Instituto Nacional de Música. Rio de Janeiro. Arquivo Nacional foto 1/12, da esquerda para a direita: Maria Luisa Bittencourt ( $\left.3^{\mathrm{a}}\right)$, Bertha Maria Júlia Lutz ( $\left.5^{\mathrm{a}}\right)$, presidente Getúlio Dornelles Vargas $\left(6^{\circ}\right)$, Jerônima Mesquita $\left(7^{\mathrm{a}}\right)$ e Henrique Aristides Guilhem, ministro da Marinha ( $\left.8^{\circ}\right)$. Ano: 1936.

$\mathrm{Na}$ data da palestra em áudio de Bertha Lutz (195_), já existiam os três parques nacionais do Brasil da Era Vargas: o Itatiaia, o Iguaçu e o nosso objeto, o da Serra dos Órgãos. Bertha Lutz explicou sobre os modelos e tipologias das unidades de proteção à natureza: o para que, de que forma, qual o regime e classificação dessas reservas naturais no mundo. Bertha Lutz voltou-se também para nossas possibilidades de criação de outros parques nacionais e de equívocos cometidos sobre esse assunto no Brasil. Também foi citada uma polêmica, sobre a categorização do Parque Nacional das Cachoeiras de Paulo Afonso - BA (Figura 2).

Continuando sua exposição, Bertha Lutz apontou duas outras questões: da escolha do modelo a ser preservado e da mudança de categoria de um parque para monumento natural, no caso das Cachoeiras de Paulo Afonso - BA. Para Bertha Lutz, aquela região baiana, apesar das suas quedas d'água e lindas cachoeiras, era uma região agreste e de caatinga, não adequada ao modelo de "parque nacional" e poderia ser recategorizada para 
MENEZES RIBEIRO, A. B; SENNA-VALE, L; MEDEIROS, M.F.T. O ativismo de Bertha Lutz para preservação da natureza: sobre os parques nacionais, fiscalização e pareceres em favor da conservação integral no estado do Rio de Janeiro Brasil (1950-1954). Ethnoscientia v.6 n. 2, especial, 2021. DOI: 10.22276/ethnoscientia.v6i2.331

“monumento natural”. Os esforços da União poderiam ser investidos em outras áreas brasileiras muito mais interessantes para um parque nacional (LUTZ, 195_; MENEZESRIBEIRO, 2019). Os ecossistemas que compõem outros domínios que não o da Mata Atlântica, embora àquela altura fossem comumente caracterizados como sendo de parca diversidade e riqueza de espécies, como no caso do domínio caatinga, mereceram a atenção conservacionista de Bertha Lutz. Na atualidade é importante que essa ideia de conservação das fitofisionomias se desenvolva cada vez mais também sob o prisma da diversidade humana, considerando as relações dos indivíduos com os recursos em seus ambientes vivenciais.

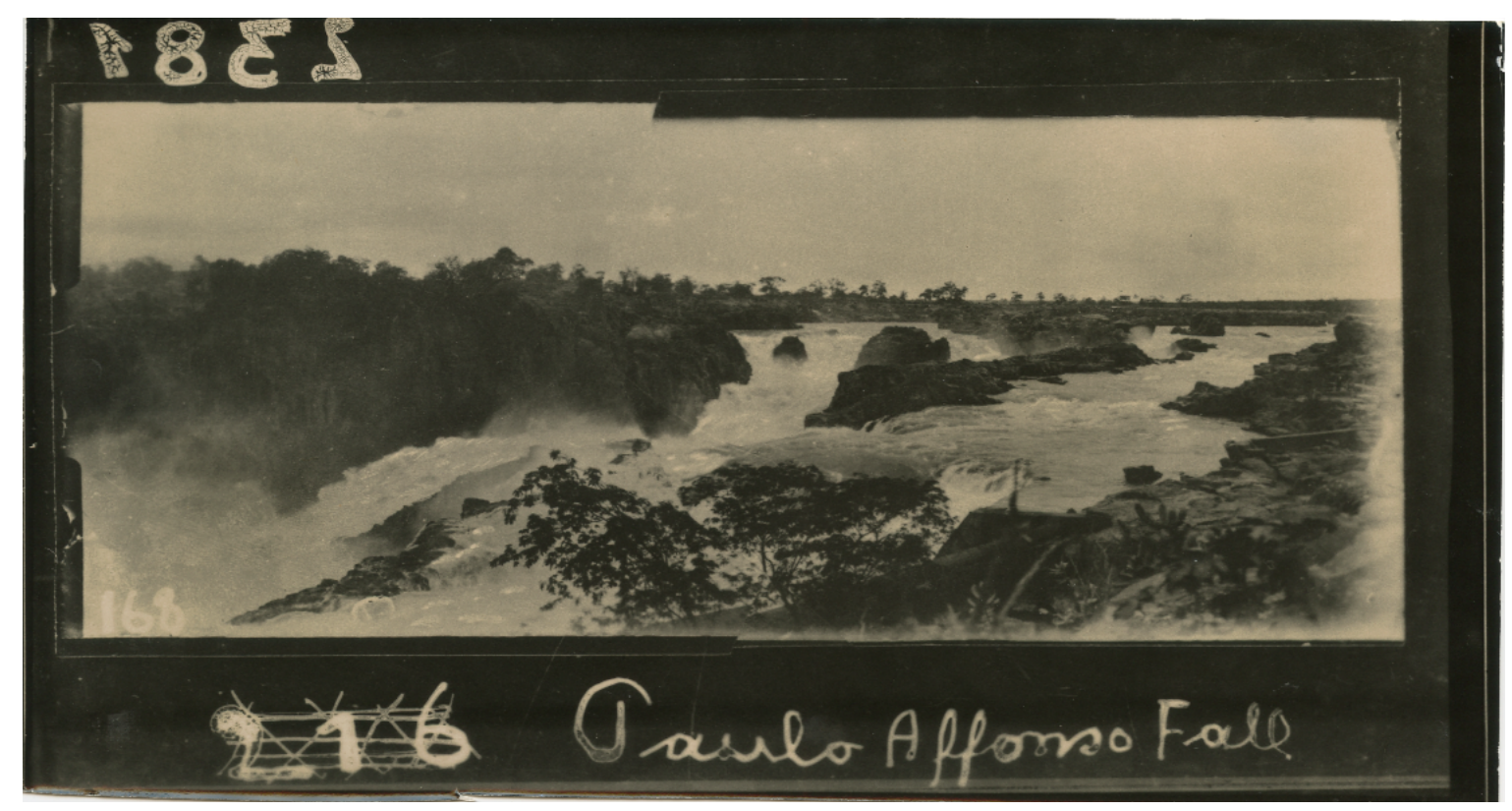

Figura 2: Cachoeiras de Paulo Afonso - BA. Fotografia de Mário Baldi. Sem data. (Fonte: Coleção da Casa da Memória de Teresópolis Arthur Dalmasso - viagem didática para a família real).

Entre outros parques e reservas, quando Bertha Lutz citou o PARNASO, chamandoo "o nosso, da Serra dos Órgãos", fez um apelo aos ouvintes para não desistirem de dar continuidade aos esforços de preservação, pois as áreas naturais, fora dos parques, ainda sofriam consequências da devastação; “fora das fronteiras das nossas unidades ainda há muito a ser feito" (LUTZ, 195_).

$\mathrm{O}$ segundo documento analisado refere-se àquele elo encontrado com informações sobre parques nacionais brasileiros e o PARNASO, na caixa particular $n^{\circ} 07$ de Bertha Lutz, no Museu Nacional em junho de 2018, redigido a máquina de escrever. Tratava-se do relatório de uma série de excursões ao Ministério da Agricultura, datado de 14 de janeiro de 1954, pelo Conselho de Fiscalização das Expedições Artísticas e Científicas do Brasil, que 
MENEZES RIBEIRO, A. B; SENNA-VALE, L; MEDEIROS, M.F.T. O ativismo de Bertha Lutz para preservação da natureza: sobre os parques nacionais, fiscalização e pareceres em favor da conservação integral no estado do Rio de Janeiro Brasil (1950-1954). Ethnoscientia v.6 n. 2, especial, 2021. DOI: 10.22276/ethnoscientia.v6i2.331

foi entregue e anexado à prestação de contas para o Ministério da Agricultura, após a visitação a diversos locais do estado do Rio de Janeiro, aos parques nacionais Itatiaia, Serra dos Órgãos e outras regiões como a Serra da Estrela, Bocaina e Passa Quatro.

As excursões a que se refere a prestação de contas anexa, foram feitas com finalidade tríplice: comparar o estado do nosso patrimônio natural atual com as descrições dos naturalistas que percorreram o século passado, as zonas ora visitadas por nós; reexaminar certas localidades clássicas que sempre atraíram as expedições científicas, cuja fiscalização compete a este Conselho, a fim de constatar se também são vítimas da sede de devastação e derrubada que caracterizam a época atual; finalmente, colher dados eco-biológicos e espécimes de anuros para levantamento faunístico da região [...] (LUTZ, 1954, p. 1).

No recibo, datado de 31 de dezembro de 1953, anexo ao Relatório da excursão de Bertha Lutz, vemos em sequência os lugares visitados. Como membro do Museu Nacional e do Conselho de Fiscalização das Expedições Artísticas e Científicas no Brasil a cientista percorreu: o Distrito Federal (que na época era o Rio de Janeiro), Petrópolis (Serra da Estrela), Três Rios, Paraibuna, Nova Friburgo (Serra da Boa Vista), Cantagalo, Teresópolis (Serra dos Órgãos), Guapimirim, Magé, Barra do Piraí, Resende, Itatiaia; Passa-Quatro e Brejo da Lapa, em Minas Gerais. No Alto Itatiaia, Mauá, Barreiras, Serra da Bocaina e volta ao Rio de Janeiro (LUTZ, 1954).

Começando a excursão em terras fluminenses, no mês de dezembro de 1953, pelo norte da Serra do Mar, Bertha Lutz e o Sr. Venâncio Fernandes seguiram de automóvel e, às vezes, a cavalo.

Fosse para moradia dos colonos ou as grandiosas obras da engenharia da autoestrada serrana Rio-Teresópolis na década de 1950, a prática comum de abertura de espaço, na época, seguia literalmente "rasgando as montanhas".

O trecho de Nova Friburgo verificou-se a modificação drástica da flora primitiva e sua substituição em grande parte por plantas exóticas. Os remanescentes de floresta são quase insulares e a fauna se acha empobrecida, embora a serra da Boa Vista ainda 
renda exemplares raros de certas espécies anuras ainda frequentes na região sul do Brasil. Na Serra dos Órgãos a floresta ascende a 100 metros, nas imediações de Teresópolis para ser substituída por formações abertas em altitudes superiores a 1800 metros. A fauna é muito rica. Em ambos os casos a proteção é fornecida pelo Parque Nacional da Serra dos Órgãos. Descemos a cavalo a Magé, em parte pela via antiga, em parte pela estrada que vem sendo rasgada. Podemos verificar de visu a destruição por loteador atrevido de uma zona riquíssima nas margens do rio Garrafão, loteador este de cujas mãos tenta o Serviço Florestal salvar estas matas pela desapropriação. Aliás a derrubada está se generalizando em toda vertente para o mar [...] (LUTZ, 1954, p. 3, grifos da autora).

Bertha Lutz descreveu, de acordo com seus objetivos, dados breves sobre a situação das florestas, ecossistemas singulares e riqueza ou ausência de espécies da flora e fauna de batráquios.

Para a cientista foi necessário comparar a situação da fauna e flora dos parques nacionais às descrições dos naturalistas que estiveram nessas mesmas regiões de Mata Atlântica. Karl Friedrich von Martius $^{3}$ (1794-1878), botânico e naturalista dos mais importantes para a botânica brasileira, residiu na região da Serra dos Órgãos, após suas viagens e expedições. Hoje a antiga casa pertence ao PARNASO, sede Guapimirim - RJ e possui um centro de memória que leva seu nome: Museu von Martius (DRUMMOND, 1997; MENEZES-RIBEIRO, 2019).

Bertha Lutz também teceu duras críticas, tanto aos brasileiros que haviam historicamente dizimado as matas do Vale do Paraíba, quanto aos estrangeiros destruindo a vegetação, pondo em risco a existência espécimes da flora brasileira:

[...] A viagem a Itatiaia, Serras da Mantiqueira, e à Serra fronteiriça da Bocaina, processou-se inicialmente pelo vale do Paraíba, em região cuja riqueza vegetal e animal primitivas estão totalmente aniquiladas. Na zona do Parque Nacional do Itatiaia a derrubada do século passado vêm sendo sustada pelo administrador atual. Na 
MENEZES RIBEIRO, A. B; SENNA-VALE, L; MEDEIROS, M.F.T. O ativismo de Bertha Lutz para preservação da natureza: sobre os parques nacionais, fiscalização e pareceres em favor da conservação integral no estado do Rio de Janeiro Brasil (1950-1954). Ethnoscientia v.6 n. 2, especial, 2021. DOI: 10.22276/ethnoscientia.v6i2.331
vizinhança do Brejo da Lapa a $2300 \mathrm{~m}$. de altitude, existe entretanto, uma colônia de italianos que estão destruindo uma das raras formações de Podocarpus, ou pinheirinho, uma das únicas coníferas nativas brasileiras. É uma tarefa nefanda, a de transformarem estrangeiros o patrimônio botânico brasileiro em carvão" (LUTZ, 1954, p. 2, grifos da autora) (Figuras 3 e 4).

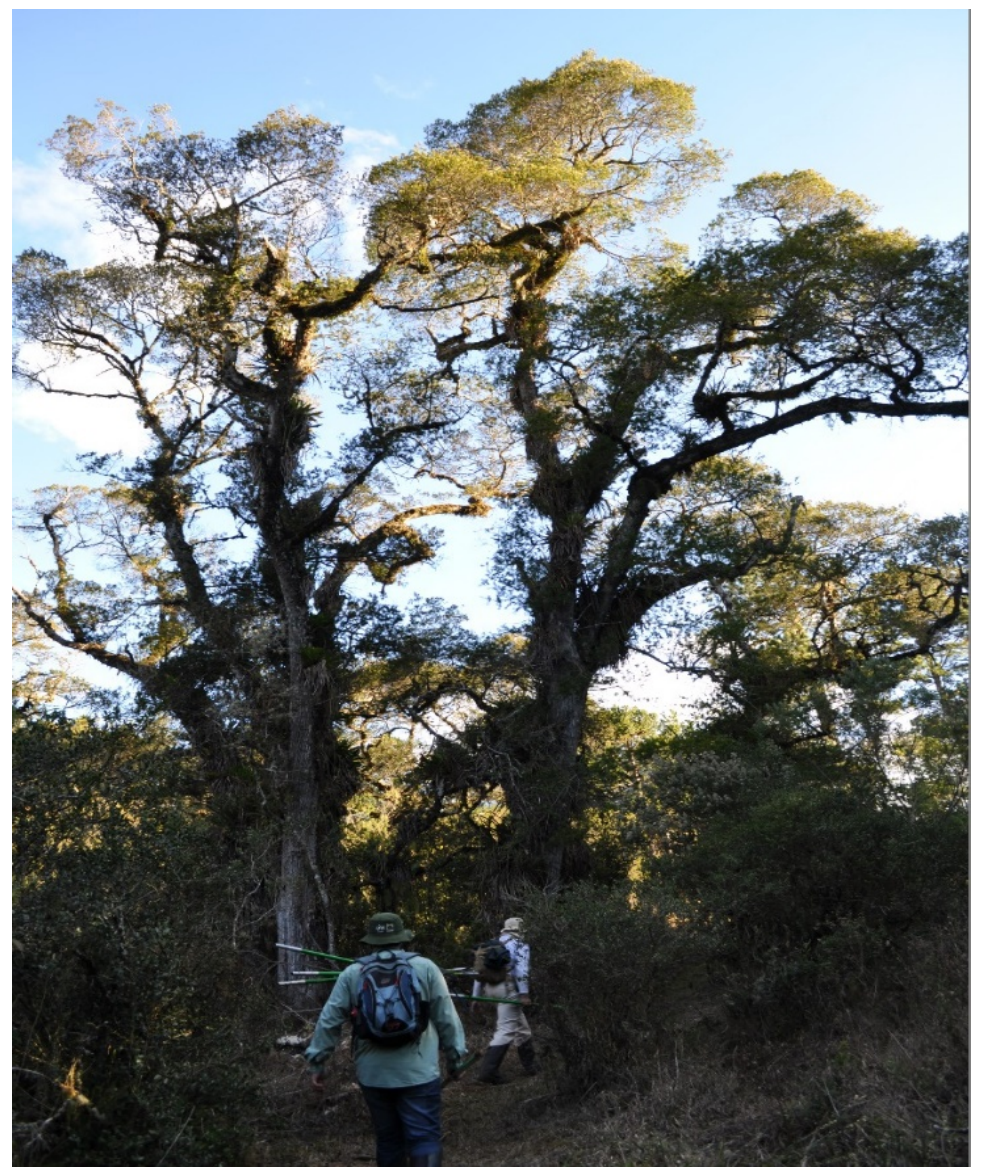

Figura 3: Podocarpus lambertii Klotzsch ex Endl., Parque Estadual da Serra do Papagaio (PESP), Alagoa MG (Fonte: Fotografias de Erika Cortines em 05 de maio de 2018). 
MENEZES RIBEIRO, A. B; SENNA-VALE, L; MEDEIROS, M.F.T. O ativismo de Bertha Lutz para preservação da natureza: sobre os parques nacionais, fiscalização e pareceres em favor da conservação integral no estado do Rio de Janeiro Brasil (1950-1954). Ethnoscientia v.6 n. 2, especial, 2021. DOI: 10.22276/ethnoscientia.v6i2.331

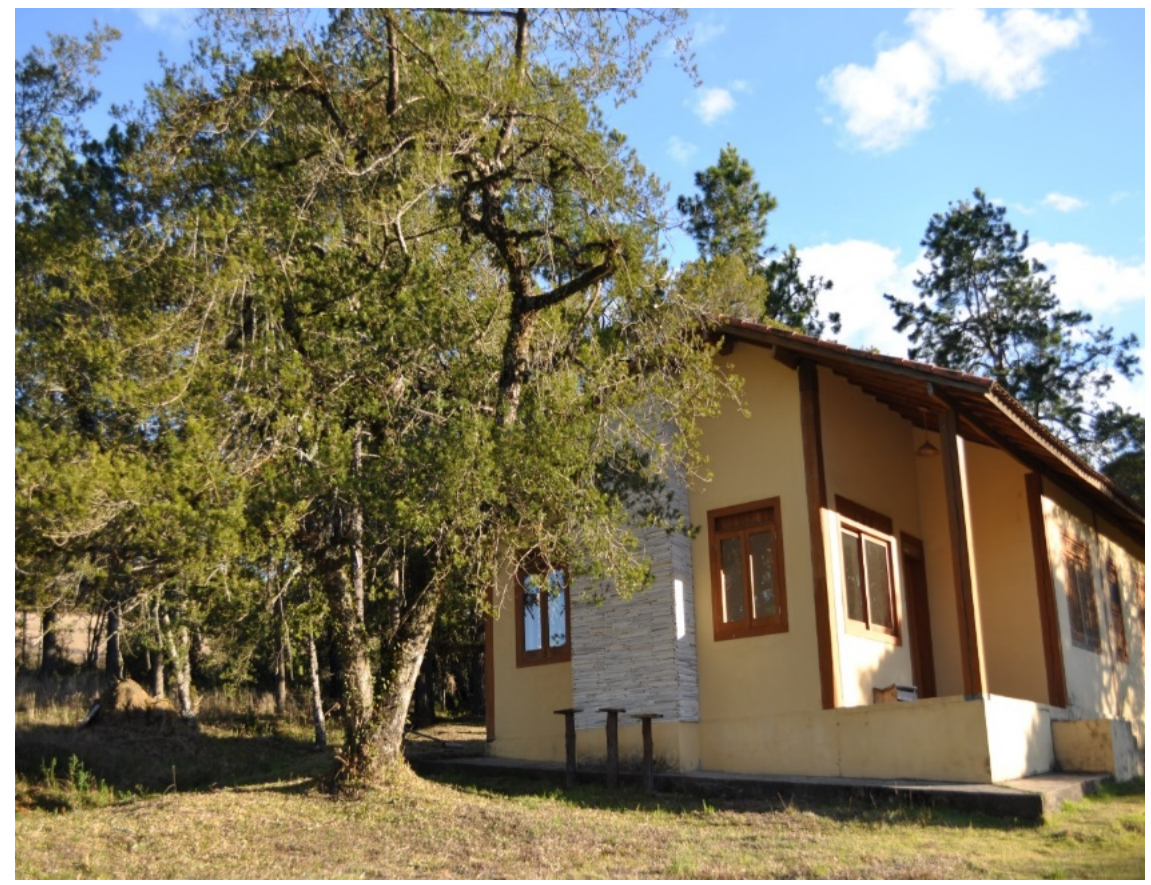

Figura 4: Podocarpus lambertii Klotzsch ex Endl., Parque Estadual da Serra do Papagaio (PESP), casa na sede do parque em Alagoa - MG (Fonte: Fotografias de Erika Cortines em 05 de maio de 2018).

Bertha Lutz recomendou, ao final, a criação de parques nacionais de Mata Atlântica nos Estado do Rio de Janeiro, São Paulo e Minas Gerais e a ampliação do PARNASO, com ênfase no papel da recuperação natural, sem intervenções:

[...] A conclusão geral que se deduz das viagens realizadas é da necessidade de ampliar os Parques Nacionais, abrangendo o do Itatiaia toda a parte elevada da Mantiqueira, sendo creado mais um outro na Serra da Bocaina de preferência desde o litoral paulista fluminense, salvando as matas magníficas, que ainda existem nas encostas, subindo pelo vale do rio Mambucaba e abrangendo o morro do Sobrado e os campos nativos da Bocaina. Também o Parque Nacional da Serra dos Órgãos merece ser ampliado e deixado entregue à natureza, de acordo com o sábio dictame romano: "Quieta non movere", isto é, deixai as coisas quietas em paz.

Rio de Janeiro, 14 de janeiro de 1954.

Bertha Maria Julia Lutz

Naturalista classe "K"

(LUTZ, 1954, p. 3, grifos da autora). 


\section{CONCLUSÕES}

As documentações analisadas colocam a cientista brasileira Bertha Lutz no pioneirismo da ciência da ecologia em Unidades de Conservação (UCs), através da observação ecobiológica in situ dos parques nacionais do Brasil.

Bertha Lutz constituiu em 1953-1954, a primeira excursão científica do que hoje chamamos de monitoramento ambiental dos parques e regiões do entorno das Unidades de Conservação integral e em áreas de relevante interesse ecológico no sudeste do Brasil.

Através do Museu Nacional e representando o Conselho das Expedições Científicas e Artísticas no Brasil, a cientista Bertha Lutz criou um método de monitoramento e fiscalização com base na história ambiental fluminense. Baseou-se nos caminhos de pesquisa de campo de antigos naturalistas e botânicos e fez uma comparação e análises do estado atual da fauna e flora. Berta Lutz utilizou a presença ou ausência de vegetação e espécimes da flora, como Podocarpus lambertii Klotzsch ex Endl. e da fauna, quando registrou que fez coletas de espécimes de anuros, como indicadores ambientais.

O diagnóstico incluiu, ao final, soluções para a conservação em unidades federais e entorno destas UCs, além da criação de novos parques em diversas localidades de interesse ecobiólogico. As diretrizes metodológicas e observações dos conflitos ambientais entre a sociedade e natureza fluminenses, descritos por Bertha Lutz, ainda hoje, são bastante atuais.

O Relatório de Bertha Lutz é considerado o primeiro relato do século XX sobre a situação geral das unidades de conservação integral brasileiras e da sociedade do entorno, com breves referências aos conflitos ambientais decorrentes da ocupação urbana ou àqueles causados pela instalação de grandes obras, como a autoestrada Rio-Planalto serrano, hoje BR116, na década de 1950.

Bertha Lutz previu a necessidade de maior intervenção federal, através do Ministério da Agricultura e a Seção Florestal, na proteção à natureza do Bioma Mata Atlântica, no estado do Rio de Janeiro e os vizinhos territórios de São Paulo e Minas Gerais. A cientista também defendeu a ampliação das fronteiras dos parques do Itatiaia e da Serra dos Órgãos, a criação de maiores áreas protegidas da federação, no modelo dos parques nacionais, como limite à devastação que se estabelecia a década de 1950 .

Bertha Lutz se fez didática, até mesmo contundentemente crítica, "em bom latim". Posicionou-se em favor do cessar absoluto das derrubadas de florestas e apontou para a proteção urgente de outros ecossistemas. Bertha Lutz cunhou uma invocação, frase de apelo 
ao governo federal em 1954: Quieta non movere! Que deixassem os parques, o entorno das unidades e o que houvesse de florestas e outros ecossistemas remanescentes, em paz.

A cientista também foi ativa pelas causas da conservação brasileira, como demonstrou em palestra e na excursão de fiscalização e monitoramento da situação do entorno dos parques nacionais. Bertha Lutz defendeu a ideia de termos muitas mais, e maiores áreas de proteção integral. As regiões por ela recomendadas, ainda demorariam décadas para serem criadas como unidades protegidas pelo Estado ou para vermos ampliados os seus territórios.

O tempo de soluções, leis protetivas e políticas socioambientais mais abrangentes, viria apenas entre as décadas de 1980-2000. Até nossos dias, ainda permanecem grandes os desafios no Brasil quanto ao cumprimento das leis conservacionistas existentes e à fiscalização dos territórios. Avançamos sessenta anos, muitas áreas protegidas e responsabilidades compartilhadas além do que Bertha Lutz previu, mas ainda almejamos em 2021, políticas públicas voltadas à conservação da natureza e dos sistemas socioecológicos que sejam mais humanistas, solidárias, ecológicas e que não sejam negociáveis, que não retrocedam as leis federais e premissas constitucionais, a tanto custo conseguidas, regulando as pressões e fazendo cessar a devastação dos nossos últimos espaços naturais originais.

A documentação de Bertha Lutz em áudio datada da década de 1950 e no relatório das excursões de 1954 são sua marca como cientista e ambientalista e nossa inspiração. Seus pareceres influenciaram políticas protetivas para que houvesse um futuro para a natureza que ainda restava, no Bioma Mata Atlântica no sudeste brasileiro.

A garantia de um futuro para a natureza pensado por Bertha Lutz se deu a partir da crítica sobre a relação dos colonos e a construção da BR-116 com a natureza. O posicionamento assumido por ela revela o foco de sua preocupação, que se voltava para a conservação integral porque, como ela mesmo disse, era corriqueira a derrubada de grandes porções de mata em toda costa leste fluminense. Do momento de Bertha Lutz, em que se buscava uma proteção das áreas naturais que as mantivesse intocáveis, chegamos na atualidade com um pensamento de conservação da natureza que se expandiu e passou a contemplar os sistemas sociecológicos e a sociobiodiversidade. Neste sentido, podemos tomar as ações promovidas por Bertha Lutz como um marco importante no movimento de se pensar a conservação da natureza, mas como etnobiólogos devemos certamente nos ocupar com a promoção de uma conservação que crie condições de existência dos sistemas sociecológicos. 


\section{REFERÊNCIAS BIBLIOGRÁFICAS}

CASAZZA, I. F. Proteção do patrimônio natural brasileiro: ciência, política e conservacionismo na trajetória do botânico Paulo Campos Porto (1914-1961). 2017. 246 f. Tese (Doutorado em História das Ciências e da Saúde) - Casa de Oswaldo Cruz, Fundação Oswaldo Cruz, Rio de Janeiro, 2017.

DEAN, W. A ferro e fogo: a história e a devastação da Mata Atlântica brasileira. 2. ed. São Paulo: Cia. das Letras, 2004. 484 p. [1 ${ }^{\text {a }}$ impressão 1996]

DRUMMOND, J. A. Devastação e preservação ambiental: os parques nacionais do Estado do Rio de Janeiro. Niterói: EDUFF, 1997. 298p.

DRUMMOND, J. A.; FRANCO, J. L. A. Alberto José Sampaio: um botânico brasileiro e o seu programa de proteção à natureza. Varia História, Belo Horizonte, n. 33, p. 129-159, 2005.

DRUMMOND, J. A.; FRANCO, J. L. A Proteção à natureza e identidade nacional no Brasil, anos 1920-1940. Rio de Janeiro: Fiocruz, 2009. 272p.

HEACOX, K. An America idea: the making of the National Parks. Washington: National Geographic Society, 2004. 192p.

KURY, L. B. Entre utopia e pragmatismo: a história natural no Iluminismo tardio. In: SOARES, L. C. (Org.). Da revolução científica à big (business) Science. São Paulo: Hucitec, 2001a. p. 105-153.

KURY, L. B. Viajantes naturalistas no Brasil oitocentista: experiências, relato e imagem. História, Ciências, Saúde - Manguinhos, Rio de Janeiro, v. 8, p. 863-880, 2001 b.

LEITE, M. L. M. Naturalistas viajantes. História, Ciências, Saúde - Manguinhos, Rio de Janeiro, v. 1, n. 2, p. 7-19, 1995.

LOPES, M. M. Proeminência na mídia, reputação em ciências: a construção de uma feminista paradigmática e cientista normal no Museu Nacional do Rio de Janeiro. História, Ciências, Saúde - Manguinhos, Rio de Janeiro, v. 15, p. 73-95, 2008.

LUTZ, B. M. J. As medidas de proteção à natureza de vários países: parques, reservas e santuários. Rio de Janeiro: Arquivo Nacional, [195-]. Dossiê em áudio. Disponível em: <http://sian.an.gov.br/sianexBR RJANRIO Q0 BLZ PIN TXT 45>. Acesso em: 26 mai. 2018.

LUTZ, B. M. J. Relatório, pareceres e prestação de contas das excursões de monitoramento ambiental, coleta científica de espécies de anuros no Estado do Rio de Janeiro e situação dos parques nacionais. Rio de Janeiro: Museu Nacional, 1954. 04p. Original digitalizado.

MENEZES-RIBEIRO, A. B. D. Natureza e política: a criação do Parque Nacional da Serra dos Órgãos (PARNASO) em 1939. 2019. 122f. Dissertação (Mestrado Profissional em Biodiversidade em Unidades de Conservação) - Escola Nacional de Botânica Tropical, Instituto de Pesquisas Jardim Botânico do Rio de Janeiro, Rio de Janeiro. 
MENEZES RIBEIRO, A. B; SENNA-VALE, L; MEDEIROS, M.F.T. O ativismo de Bertha Lutz para preservação da natureza: sobre os parques nacionais, fiscalização e pareceres em favor da conservação integral no estado do Rio de Janeiro Brasil (1950-1954). Ethnoscientia v.6 n. 2, especial, 2021. DOI: 10.22276/ethnoscientia.v6i2.331

PATACA, E. M.; PINHEIRO, R. Instruções de viagem para a investigação científica do território brasileiro. Revista Brasileira de Ciência, Rio de Janeiro, v. 3, n. 1, p. 58-79, 2005.

PATACA, E. M. Coletar, preparar, remeter, transportar. Práticas de História Natural nas Viagens Filosóficas Portuguesas (1777-1808). Revista Brasileira de História da Ciência, Rio de Janeiro, v. 4, n. 2, p. 125-138, 2011.

REBOUÇAS, A. P. Viagem ao Paraná, Caminho de Ferro Mato Grosso-Bolívia e Salto Guayra. Rio de Janeiro: Typographia Nacional, 1876. 73p.

REBOUÇAS, A. P. Diário e notas autobiográficas. Rio de Janeiro: José Olympio, 1938. 457p.

SÁ, M. R. Bertha Maria Julia Lutz. In: Kury, L. (Org.). Cadernos de viagens. Rio de Janeiro: Andrea Jakobson Estúdio, 2018. p. 186-191.

VIEIRA, A. Teresópolis: autoestrada, hotéis e Parque Nacional. Jornal O Commercio, Rio de Janeiro, 1939.

VIEIRA, A. Therezópolis: estrada de rodagem directa ao Rio de Janeiro. Jornal O Commercio, Rio de Janeiro, 1940. 